Amer. J. Bot. 58(5): 432-446. 1971.

\title{
DEVELOPMENT AND MORPHOLOGY OF STELAR COMPONENTS IN THE STEMS OF SOME MEMBERS OF THE LEGUMINOSAE AND ROSACEAE ${ }^{1}$
}

\author{
Crispin Devadas and Charles B. Beck \\ Department of Botany, The University of Michigan, Ann Arbor
}

A $\quad B \quad S \quad T \quad R \quad A \quad C \quad T$

\begin{abstract}
Two species of Leguminosae and five species of Rosaceae have been studied in an attempt to determine the relationship between the development of primary vascular bundles and their morphology, and the variation in morphology among vascular bundles of different types in the stem. A residual meristem occurs in all species. The direction of differentiation of provascular tissue and primary phloem is acropetal and continuous, but differentration of primary xylem is usually basipetal in the stem. Rare acropetal differentiation of primary xylem was observed in two species only, and in these it is restricted to axial bundles. In order to identify the different types of vascular bundles and to understand their relationship to each other and to the organs they supply, the architecture of the primary vascular system was determined. The several types of vascular bundles are highly variable in size and tracheary cell content. Of all the vascular bundles, the leaf traces are the largest and contain the greatest number of files of tracheary elements. Whereas leaf traces gradually increase in size from the levels of their divergence from axial bundles to the levels at which they enter leaf bases, axial bundles maintain a size in approximate proportion to the diameter of the vascular cylinder. Branch traces decrease in size acropetally. In axial bundles there are usually only one or two files of tracheary elements in contrast to as many as nine files in the median leaf traces of some species. In apical regions where the axial bundles are the sole means of continuous longitudinal transport in the stem, effective water and mineral conduction occur through a relatively small number of tracheary elements. In leaf traces, the much larger number of tracheary elements may have, among other functions, adaptive value in compartmentalization of transport.
\end{abstract}

The Development and morphology of the primary vascular tissues of seed plants have been studied by many workers. As a result, the events leading from their inception in the shoot apex to their complete differentiation in mature vascular bundles have been outlined in detail (Esau, 1943, 1965b). It has been established that differentiation of primary xylem is initiated in the bases of leaf primordia, and proceeds acropetally in the leaf, and basipetally into and down the stem (Esau, 1945; Girolami, 1953; McGahan, 1955; Jacobs and Morrow, 1957; De Sloover, 1958). It is also known, however, that occasional acropetal differentiation of primary xylem takes place in the stem (Scott and Priestly, 1925; Gunckel and Wetmore, 1946; De Sloover, 1958). Acropetal increase (basipetal diminution) in thickness of leaf traces has been described in several dicotyledons (Col, 1904). Disparity in size and in the distribution of conducting elements in different bundles at the same level has also been reported (Esau, 1945).

The sites of initiation and the directions of differentiation have been frequently discussed in

${ }^{1}$ Received for publication 8 December 1970.

Based on a University of Michigan Ph.D. thesis by C. Devadas. Supported in part by N.S.F. grant GB-8100X to C. B. Beck. relation to causal factors of differentiation and to the function of the vascular tissues in the shoot apex. The relationship of developmental patterns to variation in size and in distribution of mature tracheary elements in different bundles at one level, and in the same bundles at different levels has not, however, often been emphasized. Furthermore, this variation has not been carefully analyzed in relation to the morphological nature of the bundles. These objectives cannot be achieved by either a developmental study or a morphological study alone, but must involve these in combination. Information on morphological and histological variation of bundles becomes meaningful, furthermore, only if the morphological study is of a type that shows the relationship of the bundles to each other as components of an entire stelar system. In other words, the study must demonstrate the architectural pattern of the system in order that bundles of different types can be seen in relation to each other in that system.

This paper represents the results of an attempt to achieve these goals through investigations of the primary vascular systems of members of the Leguminosae and Rosaceae. The following species were used in this investigation: Cassia didymobotrya Fresen., Trifolium repens I. 
(Leguminosae); Prunus avium L., Rubus occidentalis L., Physocarpus opulifolius (L.) Maxim., Potentilla fruticosa L., and Geum canadense Jacq. (Rosaceae). Three to eight specimens of each were studied. Apical stem segments $1.5-2.0 \mathrm{~cm}$ long were fixed in suitable concentrations of CRAF solution (Sass, 1958). These were then washed in $50 \%$ ethanol, dehydrated through an ethyl-tertiary butyl alcohol series, and embedded in Tissuemat. Serial sections were cut at $10 \mu$ thickness and double-stained with safranin and fast green. Determination of the vascular patterns was made following a modification of the method of Kumari (1963). For details of this method, which involves tracing vascular bundles through a succession of transverse sections, see Devadas (1970).

Development of vascular BundLes-The bundles in the stem form a cylindrical vascular system consisting of a definite number of clearly recognizable sympodia. The sympodial pattern in which the mature vascular bundles are arranged is established during the acropetal differentiation of provascular strands. Each sympodium consists of an axial bundle that runs, uninterrupted, through the length of the stem segment, and leaf trace and branch trace bundles that diverge from it (Fig. 1, 2). The development of the vascular bundles has been studied from their inception in the shoot apex to a level of complete maturity. Since the manner of development is basically similar in all of these plants, it is described in detail primarily for Cassia, and the variations found in the other species are indicated where appropriate.

Apical meristem-The apical meristem of Cassia has a tunica-corpus organization with a singlelayered tunica. The cells of the tunica as well as those of the two or three outer layers of the corpus are elongated perpendicular to the curved surface of the apical dome. The inner cells are more irregular. Aside from this difference, the tissue of the apical meristem is homogeneous, the component cells being characterized by thin cell walls, absence of recognizable vacuoles, dense cytoplasmic contents, and large nuclei which occupy much of the space inside the cells (Fig. 3, 10). The tunica of Trifolium also consists of a single layer of cells whereas the rosaceous species studied have a 2-layered tunica.

Residual meristem-Cellular differentiation in regions which will ultimately develop into the cortex and pith takes place at slightly different levels, that in the cortical region occurring at a higher level than that in the pith. In a section taken at $110 \mu$ from the apical dome, these two regions are recognizable because their cells are larger and more vacuolate than those of the less mature region between them, the residual meristem (Fig. 4, 11). Along the length of the stem the residual meristem extends for about $140 \mu$. At $200 \mu$ from the apical dome this region is heterogeneous owing to the first visible evidence in it of four provascular strands (Fig. 5, $12,13)$. These represent the three traces to Leaf 2 and the median trace to Leaf 1 . A similar development characterizes Trifolium in which there is also a well-defined residual meristem (Fig. $6,14)$.

In Potentilla, at $50 \mu$ from the tip of the apical dome, the stem consists of a homogeneous mass of meristematic cells, and it is enveloped by leaves 1 and 2, each characterized by the presence of three traces (Fig. 7, 15). At about $80 \mu$ from the stem tip the three traces (i.e., provascular strands) of Leaf 1 are represented within the stem. At about this same level a residual meristem becomes visible through vacuolation and enlargement of cells in the pith region (Fig. 8, 16). At $50 \mu$ lower down, the traces of Leaf 2 are clearly recognizable within the stem. The residual meristem has become more restricted and welldefined at this level due to further differentiation of the regions of ground meristem that will mature into the cortex and pith (Fig. 9, 17).

Longitudinally the residual meristem can be recognized for about $100 \mu$. Its lower limit is difficult to determine because additional provascular strands continue to differentiate within it at progressively lower levels, and the remaining cells of this meristem gradually develop into the interfascicular parenchyma. A similar development characterizes Prunus, Rubus, Physocarpus, and Geum. The only significant difference in this aspect of the ontogeny among these members of the Rosaceae and those of the Leguminosae described above is that the provascular strands differentiate at a higher level within the residual meristem, i.e., closer to the apical meristem, in the rosaceous species.

Rouffa and Gunckel (1951b) did not recognize a residual meristem in the rosaceous plants they examined including Physocarpus opulifolius (L.) Maxim. and Prunus spp. Since our study clearly demonstrates a residual meristem in these and other rosaceous species, we believe that a reinvestigation might reveal its presence in other members of the family as well.

Primary vascular tissues-In all species provascular strands differentiate in direct correlation with the position of leaf primordia. The strands which first appear at higher levels are those that will mature into median leaf traces. Provascular strands appear discontinuous in longitudinal sections because they do not follow a straight course. When traced through serial sections they are found to be continuous and to differentiate acropetally.

Phloem differentiates continuously and acro- 


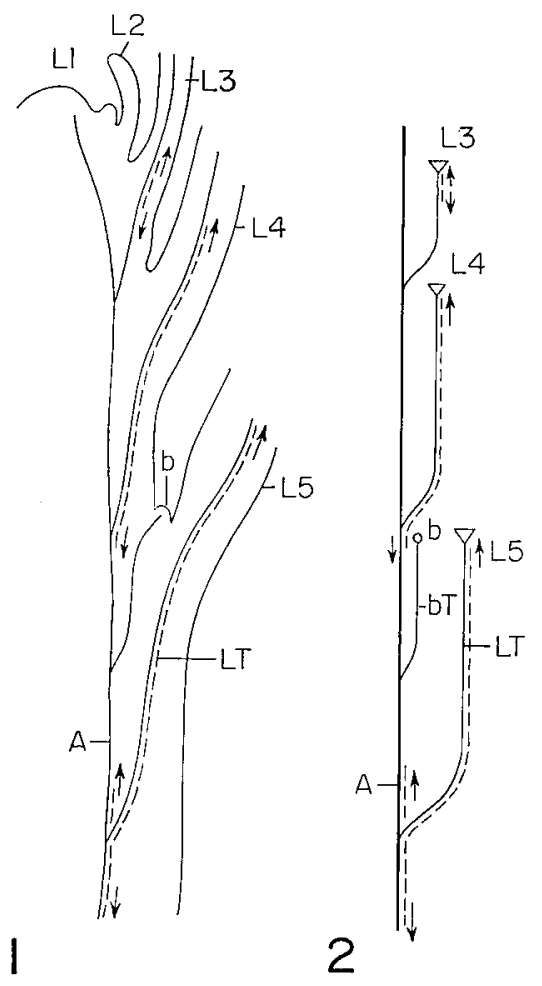

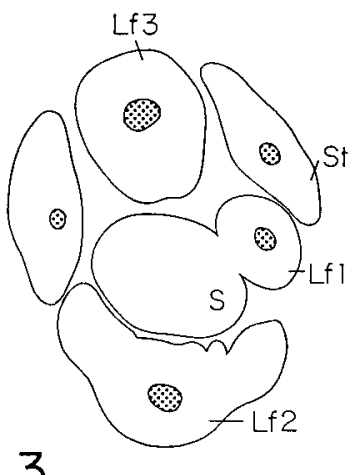

3
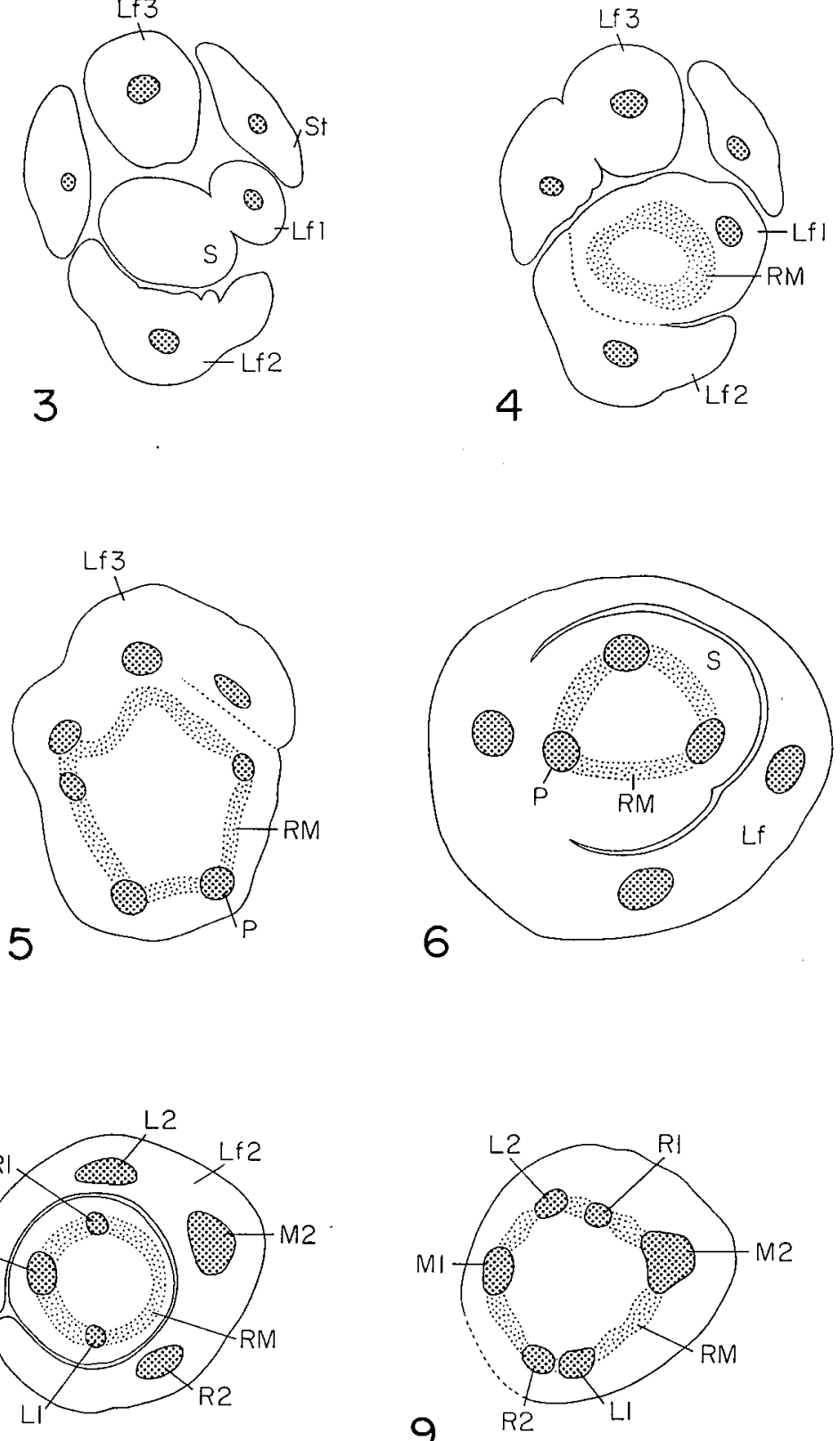

9

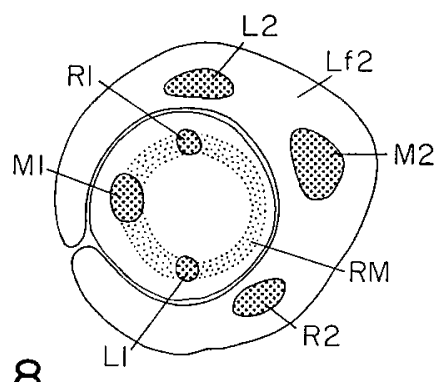

8

Fig. 1-9.-Fig. 1. Drawing of a longitudinal section of a shoot apex showing the organization of leaf traces (LT) in leaves $(L 1-L 5)$, a branch trace in an axillary bud $(b)$; and the axial bundle $(A)$ in the stem from which these traces diverge. In actual sections these bundles will not be continuous because they do not follow courses in one plane. Dashed lines represent tracheary elements in the bundles, and the arrows indicate the direction of differentiation of these elements.Fig. 2. Schematic representation of the vascular bundles in Fig. 1. The single axial bundle, and the associated leaf- and branch-trace $(b T)$ bundles together represent a sympodium. This mode of depicting vascular bundles is used in the illustrations of vascular patterns in this paper.-Fig. 3-5. Cassia didymobotrya. Camera lucida drawings of the shoot apex which correspond to Fig. 10-12. Lf 1-3, leaves; St, stipule; $S$, stem; $R M$, residual meristem; $P$, provascular strand. $\times 60$.-Fig. 6. Camera lucida drawing of a transverse section of the shoot apex of Trifolium repens which corresponds to Fig. 14. RM, residual meristem. $\times 120$.-Fig. 7-9. Potentilla fruticosa. Camera lucida drawings of transverse sections of the shoot apex which correspond to Fig. 15-17. S, stem; $L f 1-2$, leaves; $M 1-2, L 1-2$, and $R$ 1-2, represent median, left lateral, and right lateral leaf traces, respectively; $R M$ residual meristem. $\times 120$. 

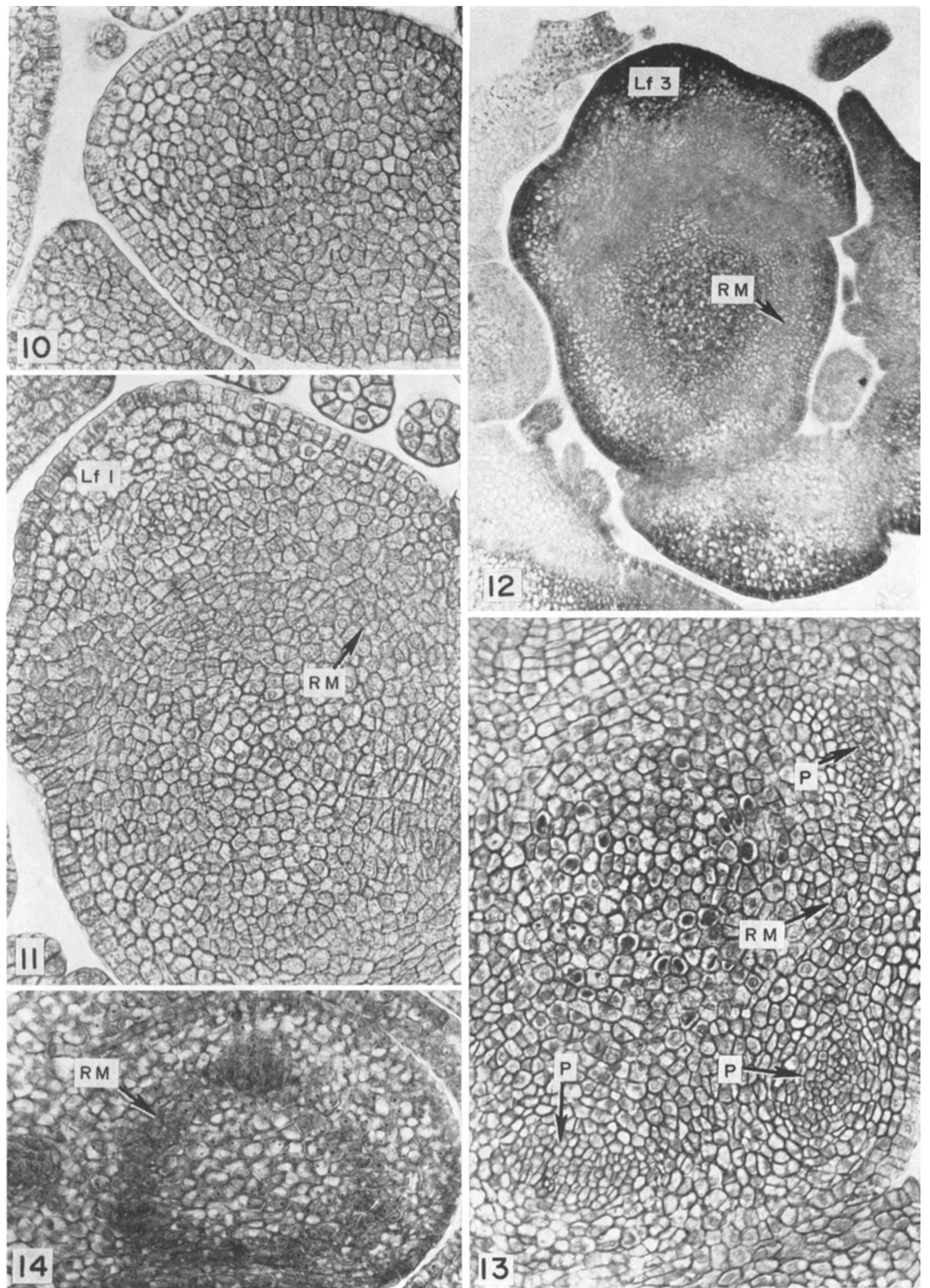

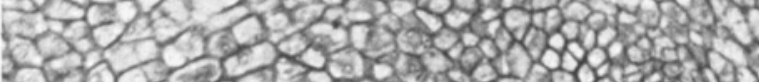

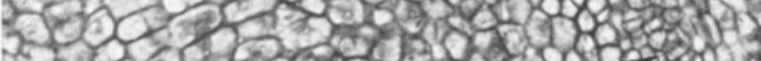
Po- 20 .

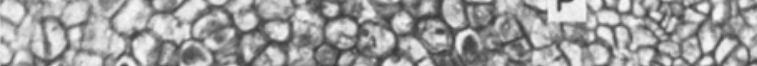

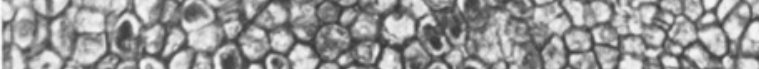

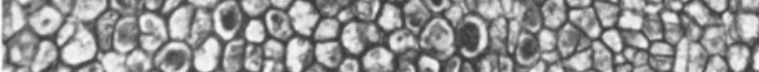

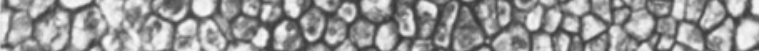

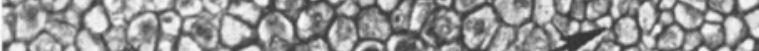

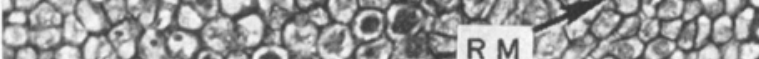

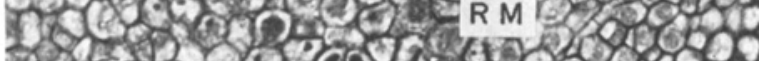

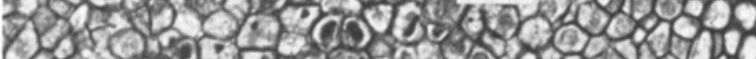
Ho 100 o

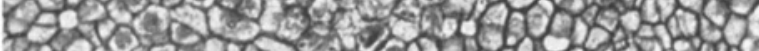

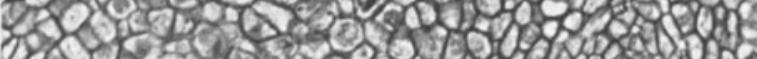

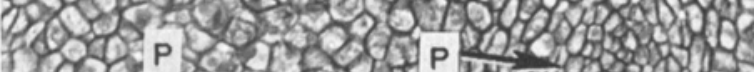

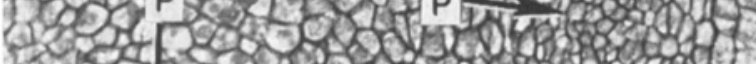

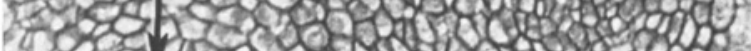

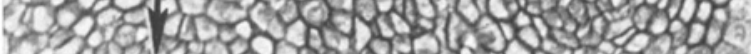

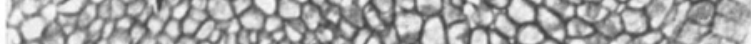
100 -

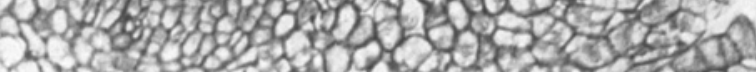

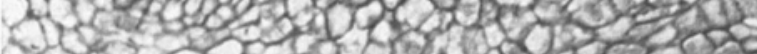

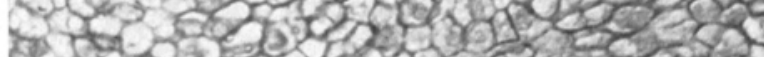
13025 ,

See page 437 for caption. 


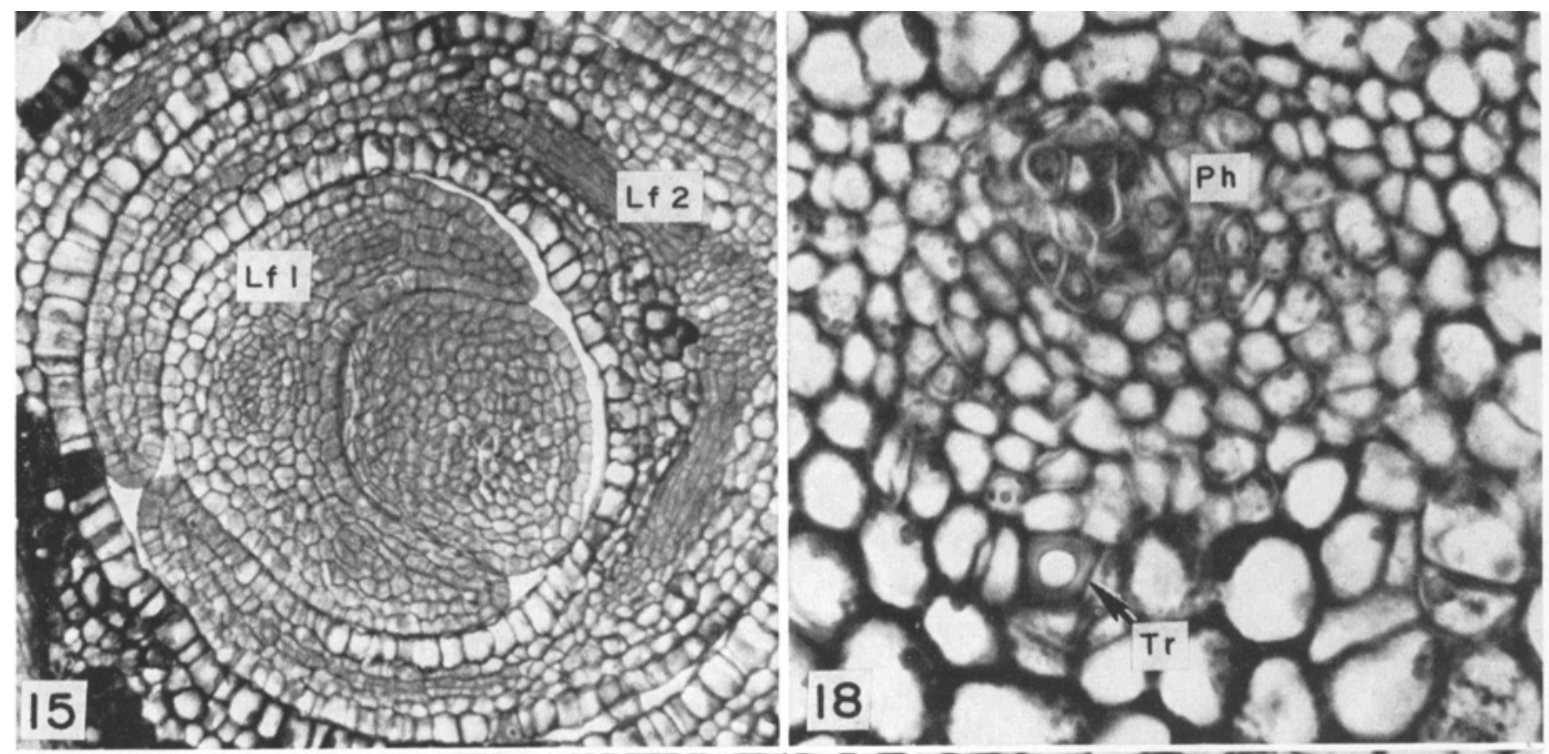

8 .

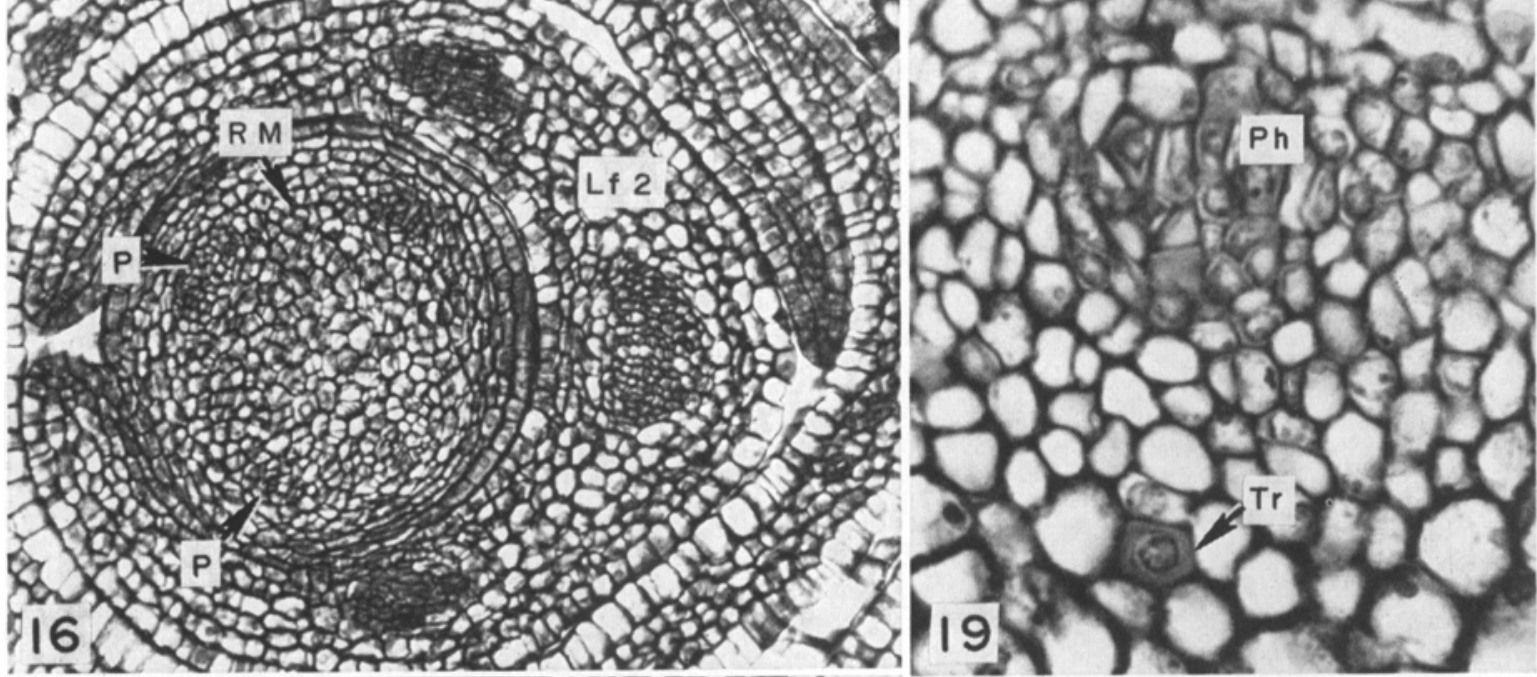

orsor.

. 5. 1.7.

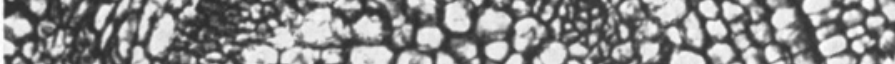

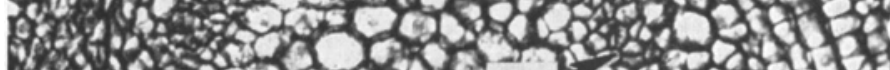
W. 1 .

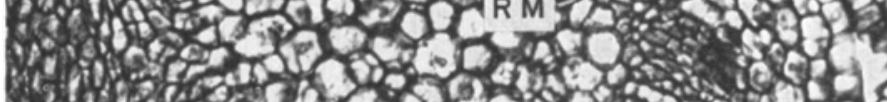

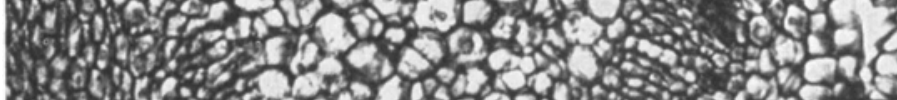

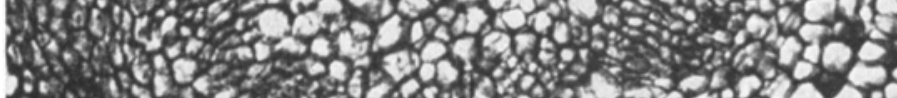

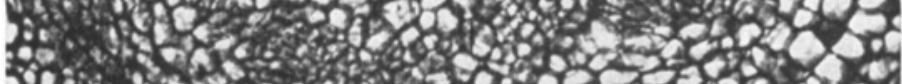

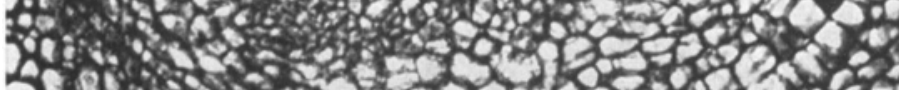
17 17.

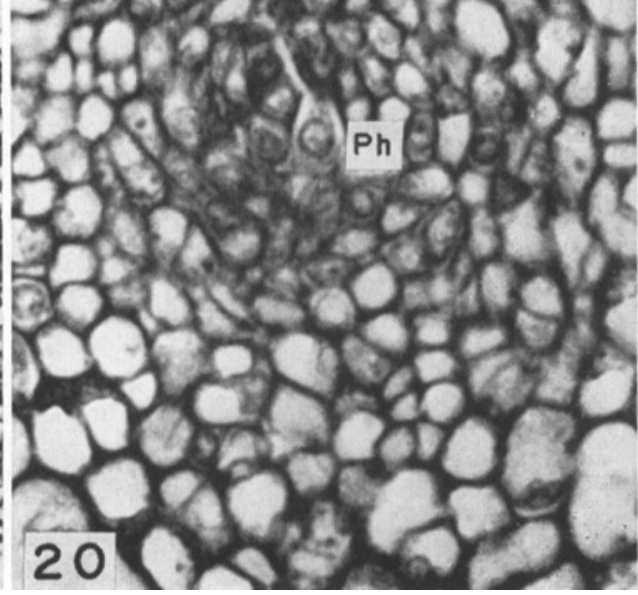


petally along the cortical side of the provascular strands. Lateral differentiation of phloem is centripetal. Protophloem cells that develop on the side of the strand adjacent to the cortex are recognizable by their relatively thick cell walls, and in the case of the sieve elements, by the empty appearance of the lumina. As metaphloem matures, the sieve elements and the companion cells in the protophloem are obliterated by the proliferation and elongation of associated parenchyma cells.

In those vascular bundles which have both xylem and phloem, the primary phloem exceeds and overarches the xylem in the tangential direction (Fig. 34). Since these vascular bundles have developed from provascular strands that are circular or elliptical in cross section (Fig. 13), the tangential expansion of the primary phloem must be attributed to the numerous cell divisions in this tissue. Although, as a result, the primary phloem forms a nearly continuous zone, a careful examination shows the presence of discontinuities in the form of narrow regions of thick-walled interfascicular parenchyma (Fig. 32, 33). This compact arrangement of the vascular bundles is characteristic of the mature stems of all species except the herbaceous Trif, lium and Geum.

Latitudinal order of maturation of primary xylem is endarch (centrifugal). As development proceeds, protoxylem cells are stretched and obliterated by elongation and enlargement of surrounding cells. This degeneration of protoxylem is most apparent in larger vascular bundles because the protoxylem cells in these mature earlier and, therefore, are subjected to greater elongation and compression than those of smaller bundles at the same level.

Longitudinal dif'erentiation of primary xylem is bidirectional in the shoot. The dif erentiation of primary xylem is initiated in leaf bases and proceeds acropetally in the leaf. In the stem, howerer, it derelops basipetally along the leaftrace bundles (Fig. 1, 2). Its development in the axial bundles is also, in most cases, basipetal, as a continuation of the process of diferentiation in the leaf-trace bundles that are connected to them (Fig. 21-23). Occasionally, acropetal dif- ferentiation of xylem elements was observed in axial bundles of the stems of Cassia (A1 in Fig. 21) and Potentilla (A5 in Fig. 22). Acropetal differentiation in the stem was not observed in any other type of vascular bundle.

Because of its basipetal differentiation, the primary xylem is discontinuous in some bundles in the shoot apices (Fig. 21-23). The basipetal differentiation of tracheary elements in leaftrace bundles in the stem has been further documented by observing the stage of development of tracheary elements in cross sections taken at different levels in the shoot apex. A section taken at a relatively high level shows a tracheary element fully mature and totally devoid of cell contents (Fig. 18). In a lower section, a tracheary element in the same vascular bundle is clearly characterized by a nucleus and cytoplasm (Fig. 19). In this bundle at a still lower level there is no evidence of tracheary cells (Fig. 20).

Morphologi of vascula Bundes-The identification of the types of vascular bundles in the stem, i.e., whether they supply leaves or axillary buds, or function as axial bundles, has been ascertained by reconstructing the patterns of the vascular systems and determining the relationship between the different types of bundles in the stem and between these and the lateral appendages of the shoot (Fig. 21-23).

The different types of bundles vary in certain characteristic morphological features, especially size and tracheary cell composition (Fig. 24, 25). For example, in the cross section of Cassia taken $15,800 \mu$ from the apical meristem and immediately below node 13 (hereafter designated as level 1, Fig. 25), the larger bundles are the median and lateral leaf trace bundles to leaves at the next three nodes above. The smaller bundles are leaf-trace bundles which supply leaves at still more distant nodes, axial, branchtrace, and accessory bundles. This size relationship between bundle types is apparent at all levels of the stem except where it is obscured by secondary growth.

From the point at which they diverge from an axial bundle, leaf-trace bundles of Cassia traverse

Fig. 10-13. Photographs of transverse sections of the shoot apex of Cassia didymobolrya. (Cf. Fig. 3-5).-Fig. 10 Apical meristem containing homogeneous meristematic cells. $\times 300$. - Fig. 11. Section from $110 \mu$ below tip of apical meristem showing the residual meristem $(R M) . \times 300 .-$ Fig. 12. Section from $200 \mu$ below tip of apical meristem, showing provascular strands $(P)$ within the residual meristem $(R M) . \times 120$.-Fig. 13. Part of the section in Fig. 12 enlarged. $\times 300$.-Fig. 14. Transverse section of the shoot apex of Trifolium repens, showing the residual meristem $(R M)$. Compare with Fig. $6 . \times 300$.

Fig. 15-17. Potentilla fruticosa. Transverse sections of the shoot apex (Cf. Fig. 7-9). Lf 1-2, leaves; RM, residual meristem; $P$, provascular strand. $\times 300$.-Fig. 18-20. Cassia didymobotrya. Transverse sections of a vascular bundle, at three successively lower levels to show the basipetal differentiation of xylem elements.-Fig. 18. Note tracheary element $(T r)$ with thickened cell wall and no apparent contents.-Fig. 19. At an intermediate level, observe the immature tracheary cell with a thinner cell wall and a nucleus.-Fig. 20 . A level in which there is no evidence of a tracheary element. $P h$, primary phloem. $\times 840$. 
TAuLE 1. Varialion in langential dimension of vascular bundles in relation to their distance from the tip of the apical meristem and the diameler of the stele. All measurements in micra.

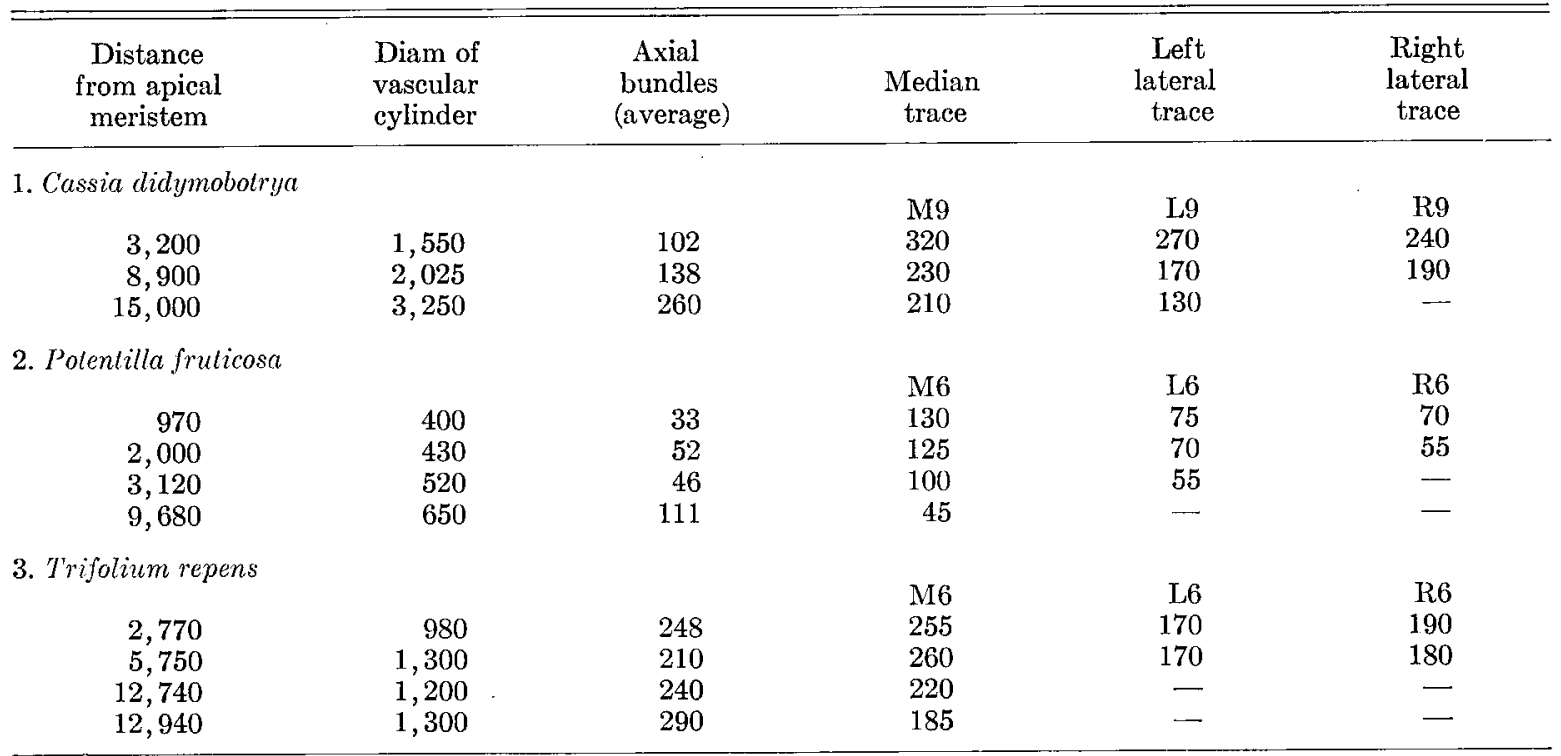

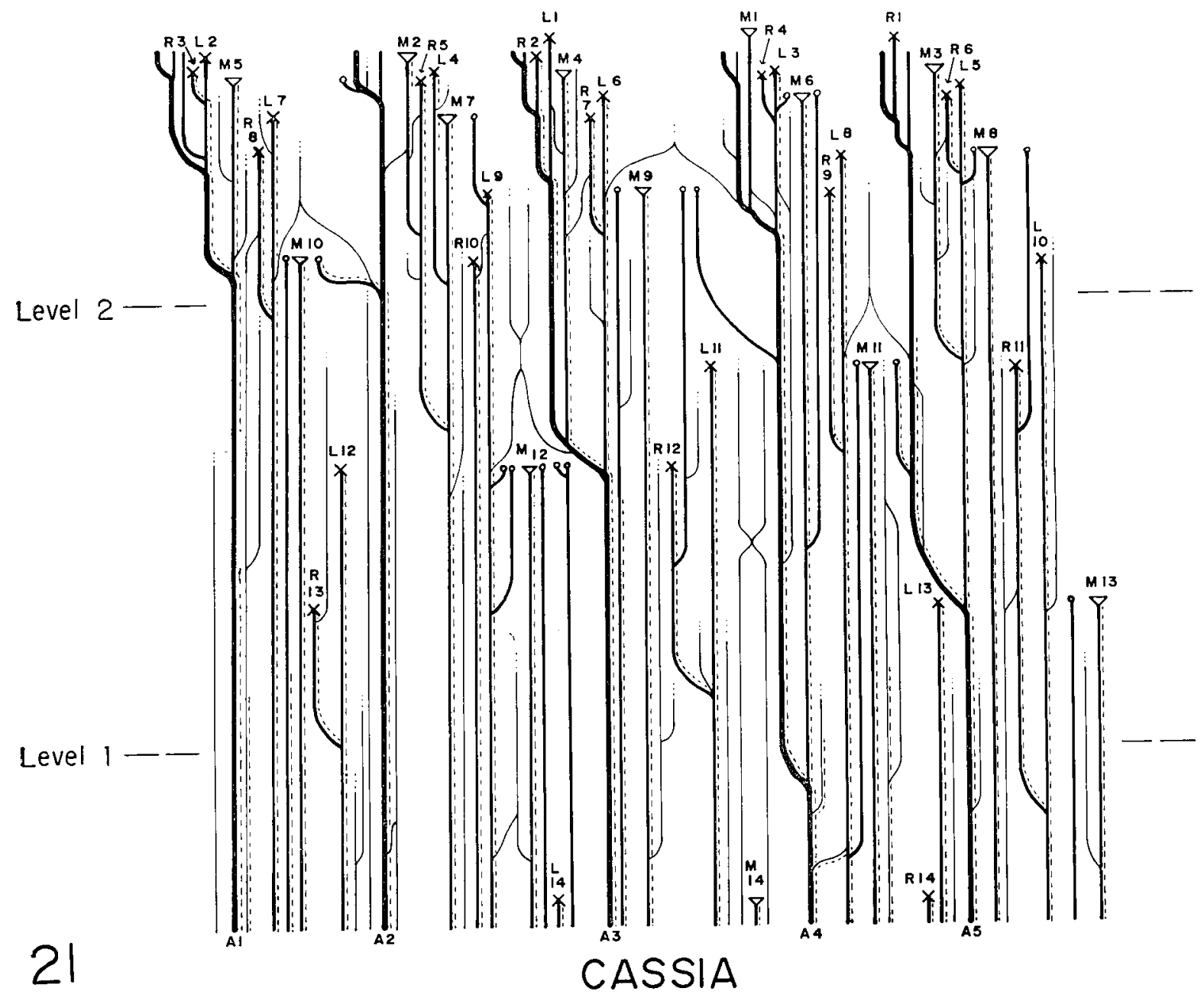



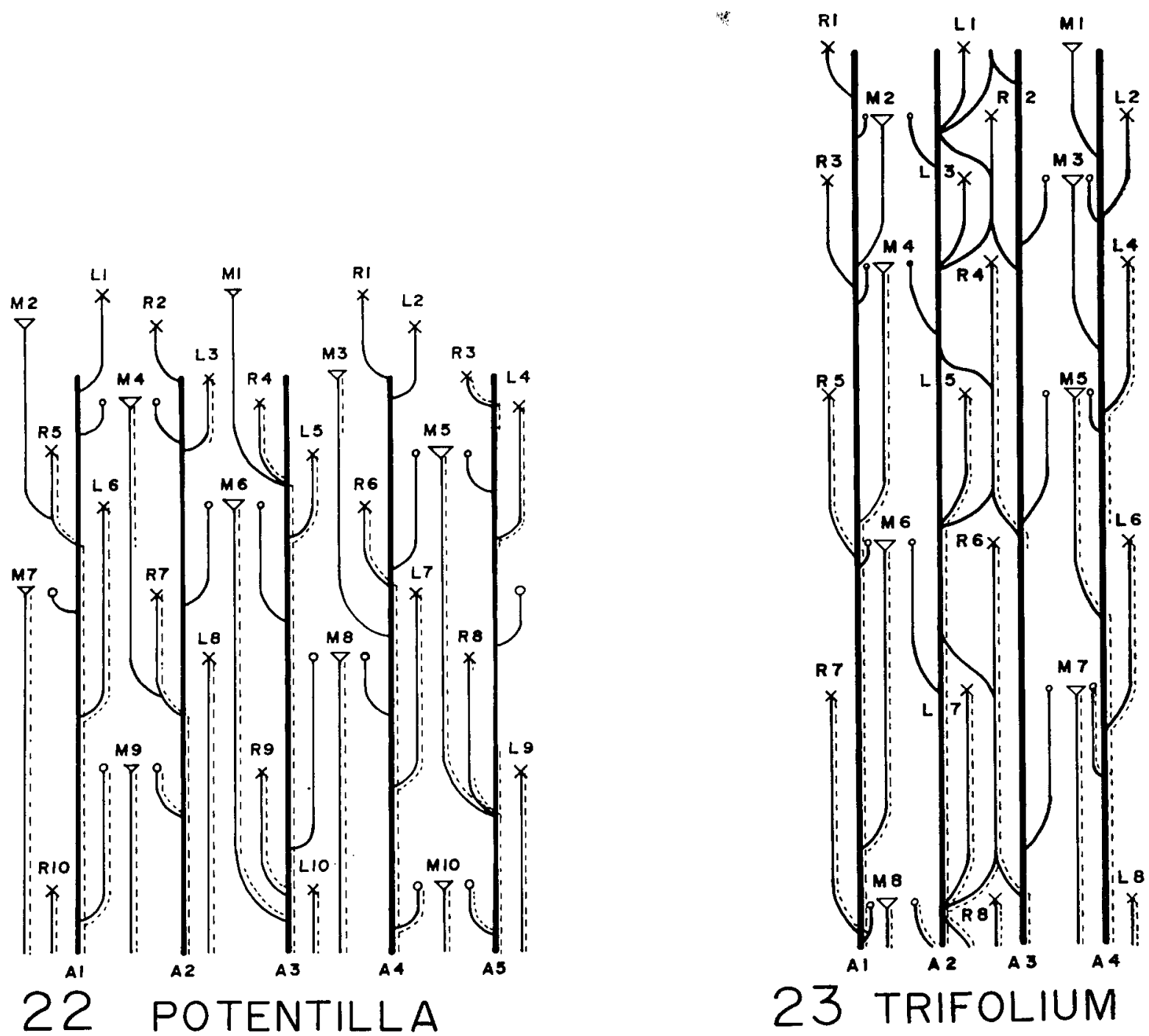

Fig. 21-23. Vascular patterns (schematic representations of primary vascular systems of the stem, drawn as if spread out in one plane) of Cassia didymobotrya, Potentilla fruticosa, and Trifolium repens, respectively. A, axial bundles, drawn with thick lines; $M, L$, and $R$, median, left lateral, and right lateral leaf traces, respectively. Branch-trace bundles are represented by small circles. Dashed lines indicate tracheary elements in vascular bundles. The thinnest continuing lines in Fig. 21 represent accessory bundles. Dots at the ends of such bundles indicate blind endings. The lower internodes have been shortened in order to conserve space.

5-8 internodes before they enter a leaf base (Fig. 21). Measurements made at different levels of individual leaf-trace bundles show that their transverse dimensions progressively increase at higher levels (Table 1 ; Fig. 26 ; also compare $M 10$ in Fig. 25, 24 and 34, 28) although, due to the gradual acropetal maturation of most tissues in the stem the diameter of the entire vascular cylinder becomes progressively smaller in the direction of the apical meristem (Table 1; compare Fig. 25, 24).

At any given level, there is a correlation between the size and the tracheary-cell composition of leaf traces. The tracheary elements develop in radial files. After the differentiation of the initial file, additional ones develop on either side after the carlier-formed ones have differentiated down to lower levels. Thus, in a given bundle, the number of files of xylem elements as viewed in cross sections, decreases at progressively lower levels. Leaf trace bundle, $M 10$, for example, has $\&$ files of tracheary elements at $5,600 \mu$ from the tip of the apical meristem (Fig. 26, 28) (level 2) and $10,200 \mu$ lower down at level 1, the same bundle has only two files (Fig. 26, 34). This might suggest that all eight files of xylem elements would, in time, develop down to the lower level. This, however, does not occur. The 
section at level 1 represents a level very near that at which secondary growth begins, and the various tissues at this level are essentially mature. It is certain, therefore, that little or no further differentiation of primary vascular tissues will take place at this level. Furthermore, an actual reconstruction of the arrangement of tracheary files in this leaf trace $(M 10)$ clearly shows that as the trace narrows toward its point of origin, the reduction in the number of files is accomplished by lateral fusion of files (Fig. 26). The lateral traces, although somewhat smaller than the median traces that will supply corresponding leaves, are essentially identical in their structure and development.

A similar morphological pattern characterizes the leaf traces of all species studied, but in the herbaceous species, especially Trifolium, they are more uniform in size and in number of files of tracheary elements at different levels than in the woody species. Although there is a reduction in the size of the leaf trace, the change is more abrupt, occurring near the point of connection between leaf trace and axial bundle (Fig. 27).

A reconstruction of the arrangement of the files in a median leaf trace $(M$ ) of Trifolium makes it clear that the number of files is nearly constant throughout the longitudinal extent of the trace in the stem (Fig. 27). There is no positive evidence of fusion of files although there is a reduction of one at lower levels. Four of the five files represented in the upper region of the trace continue down into the axial bundle and, with the one in the axial bundle at this level, form a complement of five files in the axial bundle just below the point of origin of the trace. This is reduced to one file over a distance of about one internode by lateral fusion of files. This pattern differs from that of Cassia only in that the major reduction in number of files takes place in the axial bundle rather than in the leaf trace. In both plants, there are regions in sympodia near the tip of the plant where water and mineral transport must take place through only one or two files of tracheary elements. In those apical regions of Cassia and Trifolium solely dependent on the primary vascular system, it would seem that water must be transported in the stem through only one or two files of primary xylem in each axial bundle.

The morphological differences between leaftrace bundles at the same level (i.e., in the same transverse section) clearly are related to: (1) the decrease in size of individual bundles and in the number of files of xylem elements in them at progressively lower levels, (2) the difference in size between the median and lateral bundles that supply the same leaf, and (3) the traversal of several internodes, and the consequent overlap, of different bundles supplying leaves at various nodes along the stem.

Compare, for example the difference in size and number of files of tracheary elements between the two median bundles, $M 13$ and $M 10$, at the same level (Fig. 34). Although they are both median bundles that will supply two different leaves, $M 13$ in this section is at a level in the stem at which it is about to 'enter' a leaf base whereas $M 10$ has to traverse three more internodes, a distance of $10,200 \mu$, before it 'enters' the leaf at node 10 (Fig. 21).

By contrast, median bundles $M 13$ at level 1 (Fig. 34) and $M 10$ at level 2 (Fig. 28) have certain similarities such as their shape and possession of approximately equal numbers of files of tracheary elements. Furthermore, each is the largest bundle at these levels (Fig. 25, 24). These similarities are due to the fact that each is at a comparable level in relation to the leaf it will supply, i.e., close to the level of entry into the leaf base. The differences between them at these levels, such as in actual size, in the number of mature tracheary elements, and in the amounts of provascular and primary phloem tissues, correspond to the general degree of maturity of the stem tissues at these different levels in the shoot apex.

In Cassia and other woody species, the axial bundles are in the same size category as the smaller leaf trace bundles (Fig. 24, 25). As they traverse the stem, they maintain a size in proportion to that of the vascular cylinder (Table 1). In relation to their size, however, they contain proportionately fewer tracheary elements than do trace bundles at the same level (Fig. 28, 34). In fact, as a result of basipetal differentiation, there may be no tracheary elements at all in certain segments along the length of the axial bundles $(A 3$ in Fig. 21; $A 3$ and $A 4$ in Fig. 23). Other examples of such discontinuities in tracheary elements in axial bundles are illustrated by bundles $A 1$ in Fig. 21 and $A 5$ in Fig. 22. The tracheary cells in the upper levels of these bundles differentiated basipetally as a continuation of differentiation in the trace bundles connected to them above. In the section at level 2 this xylem is represented by two elements in separate files (Fig. 30). The xylem in the lower part of the same bundle at level 1 differentiated acropetally and is represented by three tracheary elements in two files (Fig. 32). Continuity would have been established, of course, following further differentiation. Acropetal differentiation of primary xylem in stem bundles have been rarely observed in this study and only in axial bundles.

In general, branch-trace bundles which supply axillary buds are comparable in transverse dimensions to the smaller leaf-trace bundles, sometimes smaller (Fig. 24, 25, 31, 33). They decrease in size, however, from the point of their origin to the level at which they enter a bud or lateral branch. Differentiation of primary xylem is consistently basipetal. Although often illustrated as longitudinally very short and diverging abruptly, almost transversely, from the main vascular 


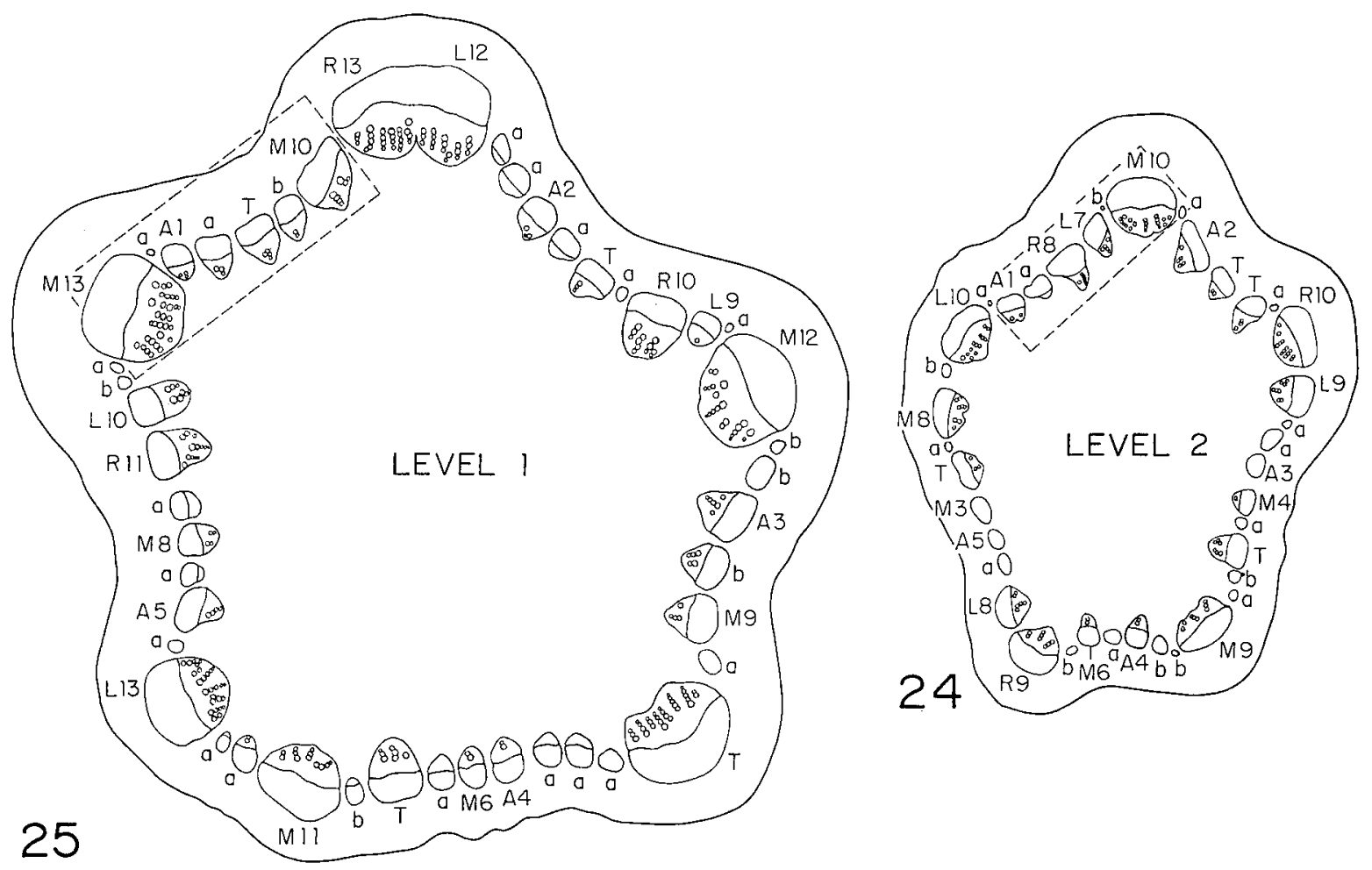

Fig. 24, 25. Cassia didymobotrya. Camera lucida drawings of transverse sections of the stem at 2 levels (levels 2 and 1 , respectively), drawn at the same scale to show types and variation in size of vascular bundles, and the distribution of tracheary elements in them. $\times 30$.

cylinder, the branch traces of several species we have studied vary greatly in length. In Cassia they commonly extend through from one to five or more internodes; in Trifolium, through one internode; and in Potentilla, through from less than one to two internodes (Fig. 21-23).

In addition to the axial bundles, leaf traces, and branch traces, there are a large number of small vascular bundles in the stem of Cassia which we term accessory bundles. They are considered accessory for the following reasons: (1) They either end blindly or form interconnections between bundles; (2) they do not form part of the vascular supply to leaves or axillary buds; and (3) their points of origin are varied, and they do not conform to any orderly pattern within the stelar system. In size, as observed in transverse section, they range from that of the smaller leaf traces to a few micra across. Their lengths vary from a few micra to about $14 \mathrm{~mm}$. At level 1 there are 29 of these bundles of which only three of the larger ones have both xylem and phloem (Fig. 25, 32), the remainder being composed only of phloem. At level 2 there are 17 accessory bundles and these consist exclusively of primary phloem (F̈ig. 28). At about $800 \mu$ from the apical meristem, in the same stem segment, there are only four of these bundles, suggesting that they do not differentiate much closer to the apical meristem. It is clear that most of the accessory bundles are composed solely of primary phloem, throughout their length, only a few of the larger ones containing any primary xylem. From near its point of origin, each bundle gradually becomes smaller at progressively higher levels until it either ends blindly within the parenchyma of an interfascicular region or connects with another bundle (Fig. 21). Although they often interconnect with a bundle of different type, they may also interconnect with another accessory bundle. Such intercomnections in Cassia occur in the internode just above points of entry of a median trace into a leaf base (Fig. 21). On the basis of our data we are unable to suggest an explanation for this feature, or to provide any insight into its possible significance. Accessory bundles are also present in much smaller numbers in Trifolium. They do not occur in the rosaceous plants that were examined.

Discussion-The apical meristem is generally defined as the part of the shoot apex distal to the youngest leaf primordium or the youngest node (Esau, 1965a). Although its form may fluctuate during a plastochron, in most plants it is dome-shaped and, to some degree, extends beyond the point of attachment of the youngest leaf 


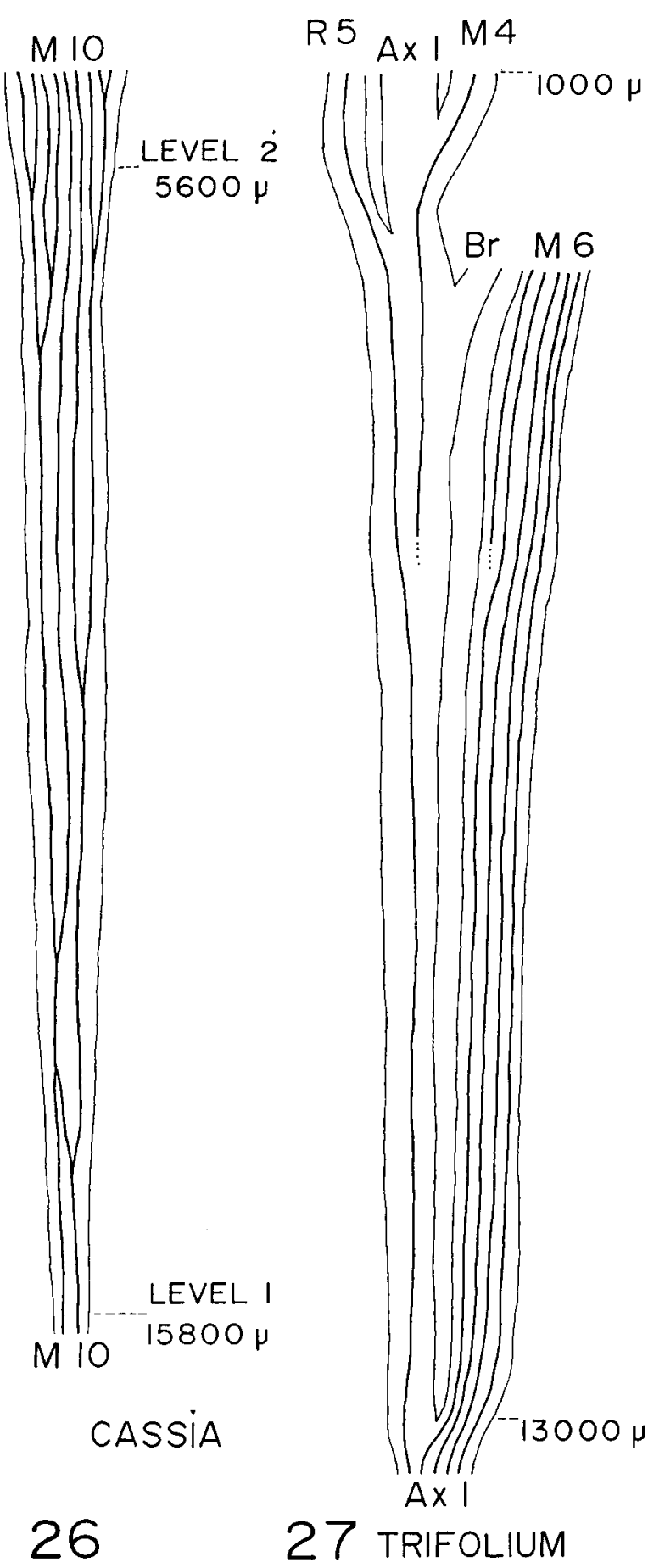

Fig. 26, 27. Diagrammatic representations of vascular bundles to show the number and arrangement of files of tracheary elements. The width of the bundles and the interfascicular regions are drawn to the same scale. The length of the bundles has however been greatly reduced.-Fig. 26. Cassia didymobotrya.-Fig. 27. Trifolium repens. primordium throughout this interval. In Physocarpus, however, only the two layers of the tunica extend above the point of attachment of the youngest leaf primordium, and in Potentilla the tip of the apical meristem and the point at which the youngest leaf is attached are at the same level. A similar condition has been described by Rouffa and Gunckel (1951a) in the members of the Rosaceae which they studied and also in other dicotyledons by Reeve (1948). Therefore, in such cases, the apical meristem has to be delimited on the basis of the alignment and cytohistologic characteristics of its cells. In such cases, furthermore, it is impossible to make a clear-cut distinction between the basal part of the apical meristem and the upper limit of the residual meristem.

The appearance of residual meristem clearly precedes the differentiation of provascular strands in Cassia (Fig. 11). In Potentilla and the other rosaceous members studied, however, provascular strands differentiate very close to the apical meristem, and the first visible delimitation of residual meristem coincides with the first evidence of differentiation of provascular strands (Fig. 16).

Certain 19th century anatomists, and others, (Esau, 1943) have considered the cylindrical region, now termed residual meristem, to be a direct meristematic precursor of the vascular tissues. More recent workers (Kaplan, 1936, 1937; Esau, 1943, 1965b) consider it to be a transitional region, closely related to the apical meristem, in which the direct primary vascular meristems, i.e., the provascular strands, differentiate. Our observations, especially in the rosaceous species, lend support to this latter view. They do not, however, necessarily invalidate the idea that the residual meristem is the direct precursor of the vascular cambium, or at least the interfascicular part of it. Clearly, the tissue within the provascular strands from which the fascicular cambium differentiates differs from that of the residual meristem. In those cases where interfascicular cambium develops through dedifferentiation of interfacsicular parenchyma (many herbaceous species), none of the vascular cambium is derived directly from residual meristem. It has been suggested by Eames and MacDaniels (1947) and Philipson and Ward (1965) that in some other plants, especially woody forms, in which the vascular bundles unite into an apparently continuous cylinder, all of the vascular cambium may develop directly from provascular tissue. In our study we considered the possibility that the interfascicular cambium might differentiate directly from residual meristem which, if true, would support the early concept of the residual meristem as a direct vascular meristem. In the five woody species studied, the vascular bundles of all do appear superficially to become contiguous through lateral expansion. We believe, however, that in all cases there are 

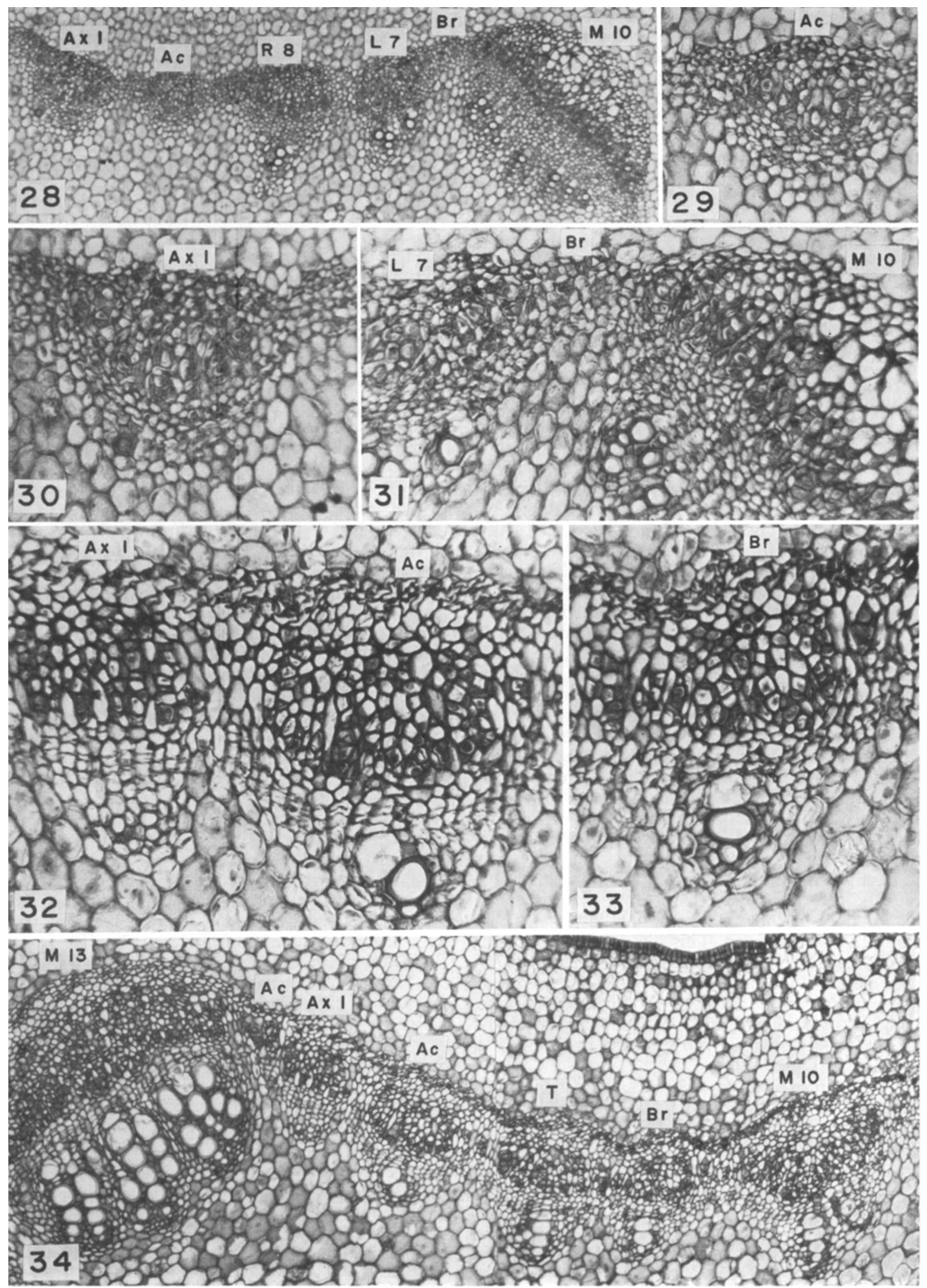
one to several files of cells between vascular bundles that represent the original residual meristem (Fig. 32). It is in this region (within its inner margin in Cassia, but more centrally located in other species) that the interfascicular cambium differentiates. We have not been able to decide, however, whether this tissue is still meristematic or whether cambial development in these regions involves dedifferentiation. Consequently, we cannot accept without question the unequivocal view of Esau (1965a) that the interfascicular cambium develops through resumption of meristematic activity of interfascicular parenchyma. This view, nevertheless, seems to more nearly apply to the species we have studied than that of Philipson and Ward (1965). We mean in no way, however, to suggest that the view of Philipson and Ward might not accurately represent the early ontogeny of the interfascicular cambium in some plants. There is no doubt that the problem of cambial origin must be given further study before it will be solved.

The presence of a continuous, cylindrical residual meristem in a plant with a dissected primary vascular system has been taken by some as an indication of a phylogenetically more primitive form of the system. We cannot accept this total adherence to Haeckel's biogenetic theorem. This theorem is especially vulnerable, we believe, when applied to a tissue region within a stem characterized by an indeterminate type of development. In this regard we agree with Carlquist (1969). Since the residual meristem may be present in shoot apices of stems in which the vascular bundles are compactly arranged as well as those in which they are separated by wide interfascicular regions, in arborescent and herbaceous plants, and in members of both phylogenetically primitive, ranalean families and advanced ones such as the Compositae, we believe it highly unlikely to have any phylogenetic significance.

In all plants studied, the tangential dimension of the leaf traces increases from the point of divergence of the traces to the level of their entry into a leaf base. This change in dimension is greatest in the arborescent species. In herbaceous species it occurs abruptly near the point of trace divergence with little further increase throughout its longitudinal extent in the stem. In the woody species, the increase in dimension is gradual (Fig. 26, 27).

The form of the traces seems to be related to the manner of development of the bundles. In each trace bundle, although the differentiation of phloem is acropetal and continuous, a larger number of phloem cells differentiate at levels close to the point of entry into a leaf base than at lower levels. It is apparent, furthermore, particularly in the woody species, that at the most mature level studied $(1.5-2 \mathrm{~cm}$ from the tip of the apical meristem) there are significantly fewer files of tracheary elements near the point of origin from the axial bundle than at a level just below the entry into a leaf base. There are, for example, in Cassia only two files of tracheary elements in a median trace $(M 10)$ at a level near its origin (Fig. 26), but eight files at a higher level near the node at which it will supply a leaf. Since secondary growth in the woody species begins at about $1.5-2 \mathrm{~cm}$ from the stem tip, it is apparent that this variation in structure in different parts of the median leaf traces is a feature of the mature traces. This same type of variation characterizes the lateral traces as well but in lesser degree. As might be expected, the leaf traces are most similar to the axial bundles at levels closest to their points of origin from the axial bundles. In general, mature axial bundles and branch traces resemble each other. As observed in transverse section, axial bundles are conspicuously smaller than the leaf trace bundles that supply the leaf at the node immediately above, and show little variation in size and number of tracheary elements at different levels. It is clear, however, that, with the exception of accessory bundles, where they occur, axial bundles are characterized by fewer tracheary elements than any other type in the primary vascular system of the stem.

Although variation in size of different bundle types is less conspicuous in the herbaceous species than in the woody, it is, nevertheless, a feature of the former as is the striking variation in tracheary cell content between leaf traces and axial bundles. As in the woody species, the axial bundles contain fewer files of tracheary elements than leaf traces that diverge from them, at least over part of their length. In Trifolium, segments of axial bundles just above points of divergence of traces usually contain only one or two files, sometimes none, whereas a median trace at the same level will contain from 4-6 files (Fig. 27). Trifolium differs from Cassia, however, in that the files of tracheary elements remain nearly constant in number throughout the longitudinal extent of a leaf trace, and extend down into the axial bundle for about one internode before being reduced to one or two in number by lateral fusion of files. Sections taken at levels below the upper limit of secondary activity provide conclusive evidence that this pattern is not simply the result of incomplete development.

Fig. 28-34. Cassia didymobotrya.-Fig. 28-31. Vascular bundles of different types at level 2, 5600 $\mu$ from the tip of the apical meristem.-Fig. 32-34. Vascular bundles of different types at level $1,15800 \mu$ from the tip of the apical meristem.-(Fig. 28 and 34 correspond to the rectangular areas marked in Fig. 24 and 25, respectively.) $A x$, axial bundle; $A c$, accessory bundle; $M, L$, and $R$, median, left lateral, and right lateral leaf traces respectively; $B r$, branch-trace bundle; $T$, a leaf-trace bundle that bifurcates at a higher level into $R 8$ and $L$ 7. Fig. 28, 24. $\times 120$; Fig. 29-33. $\times 300$. 
Dormer (1945) has suggested that closed primary vascular systems, i.e., those in which sympodia are interconnected, may be related to a loss of cambial activity and the resultant absence of an enclosing cylinder of secondary xylem. A concurrent evolution of interconnections between sympodia might, he believes, have functional significance in tangential transport and, thus, adaptive value.

We have considered, similarly, the possibility that the great variation in bundle size and in number of files of tracheary elements in vascular bundles of different types might be related to the presence or absence of secondary xylem. Certain characteristics of the primary vascular system of the woody species suggest that alone it might be a highly inefficient conducting system.

We have considered the possibility that the presence of only two files of vessels in M 10 (Fig. 34) at a lower level might limit the efficiency of transport in this bundle which at a higher level contains nine files of conducting elements (Fig. 28 ). If such a problem were to exist in the few millimeters of stem tip lacking secondary growth, it would clearly not have any appreciable effect on water transport in Cassia (and, presumably, other woody plants) because secondary xylem is in contact with the region of the leaf traces in which a large number of files develops, and this region together with the secondary xylem would, no doubt, provide an adequate system of supply to the leaves.

In an herbaceous species such as Trifolium, however, with a similar organization of primary tracheary elements, one might suspect that the lack of cambial activity in the apical 3 or $4 \mathrm{~cm}$ of the stem might have imposed a more serious problem of conduction. Clearly this is not the case, however, since Trifolium is a widespread, successful genus. Obviously the axial bundles alone do provide an efficient conduit for water conduction through the region of the stem lacking secondary xylem. The segments of bundles containing only one file of tracheary elements clearly do not form a barrier to efficient transport in T'rifolium.

Although this study is not sufficiently comprehensive to serve as a basis for serious criticism of Dormer's interesting hypothesis, our approach to the analysis of the adaptive value of conducting structures makes us suspect that connections between sympodia might not, in fact, have evolved in response to selection pressure for tangential transport. In Trifolium, only two of the four axial bundles are interconnected. Interestingly, the largest number of leaf traces, and all of the median traces, arise not from these, but from the other axial bundles in the system (Fig. 23). When one considers, further, that many herbaceous plants which produce no secondary tissues over long apical segments of stem have open systems, and others which produce no secondary tissues at all, as in the Ranunculaceae (Ezelarab and Dormer, 1963), have only irregularly closed primary vascular systems, Dormer's rationale loses impact.

If, as we have suggested above, only a few vessels are essential for efficient water transport along an axial bundle, one must consider the possible adaptive value of the much larger number of files of tracheary elements in the leaf traces in both the woody and herbaceous species. It has been suggested by our colleague, Dr. Conrad Yocum (personal communication), that the greater number of files in the bundles that supply leaves might, through a compartmentalization of water flow, have adaptive value as a protection against total loss of function of the vascular supply in the outer cortex and in the leaf base where it would be more prone to injury and consequent entrance of air than in the axial bundles or the basal parts of the leaf traces. It seems probable, furthermore, that the large number of files of tracheary elements is essential nearer the blade of a leaf because the trace will subsequently divide many times in the formation of the venation system. It is not unlikely that the larger, more woody traces in the leaf base function in mechanical support as well.

\section{LITERATURE CITED}

CArlquist, S. 1969. Toward acceptable evolutionary interpretations of floral anatomy. Phytomorphology 19: $332-362$.

Col, A. 1904. Recherches sur la disposition des faiceaux dans la tige et les feuilles de quelques Dicotyledonés. Ann. Sci. Natur. VIII. Bot. 20: 1-288.

DE Sloover, J. 1958. Recherches sur l'histogénèse des tissus conducteurs. II. Le sens longitudinal de la différenciation du procambium, du xylème et du phloème chez Coleus, Ligustrum, Anagallis et Taxus. Cellule 59: 55-202.

Devads, C. 1970. A comparative study of development and morphology of the primary vascular system of some species of Leguminosae and Rosaceae. Ph.D. Thesis, University of Michigan, Ann Arbor.

Donmer, K. J. 1945. An investigation of the taxonomic value of shoot structure in angiosperms with special reference to Leguminosae. Ann. Bot. 9: 141-153.

Eames, A. J., AND L. H. MacDanigls. 1947. An introduction to plant anatomy. McGraw-Hill Book Co., New York.

E.ssu, K. 1943. Origin and development of primary vascular tissues in seed plants. Bot. Rev. 9: 125-206.

-_- 1945. Vascularization of the vegetative shoots of Helianihus and Sambucus. Amer. J. Bot. 32: 18-29.

- 1965a. Plant Anatomy. 2nd. Edn. John Wiley and Sons, New York.

- - 1965b. Vascular differentiation in Plants. Holt, Rinehart and Winston, New York.

Ezalarab, G. E., ANi K. J. Dormer. 1963. The organization of the primary vascular system in Ranunculaceae. Ann. Bot. N.S. 27: 23-38.

Ginoldmi, G. 1953. Relation between phyllotaxis and primary vascular organization in Linum. Amer. J. Bot. 40: 618-625. 
Gunckel, J. E., And R. H. Wetmone. 1946. Studies of development in long shoots and short shoots of Ginkgo biloba L. II. Phyllotaxis and the organization of the primary vascular system; primary phloem and primary xylem. Amer. J. Bot. 33: 532-643.

JAcous, W. P., AND I. B. Morrow. 1957. A quantitative study of xylem development in the vegetative shoot apex of Coleus. Amer. J. Bot. 44: 823-842.

I I Plan, R. 1936. Die Differenzierung des Sprossscheitelmeristems bie einigen Piperaceen, kleinblättrigen Dikotylen, Monokotylen und Gymnospermen. Planta 25: $302-306$.

-. 1937. Ueber die Bildung der Stele aus dem Urmeristem von Pteridophyten und Spermatophyten. Planta 27: 224-268.

Kumari, G. K. 1963. The primary vascular system of gymnosperms. Ph.D. Thesis, University of Michigan, Ann Arbor.

McGaHAN, M. W. 1955. Vascular differentiation in the vegetative shoot of Xanthium chinense. Amer. J. Bot. 42: $132-140$.

Philipson, W. R., and J. M. Ward. 1965. The ontogeny of the vascular cambium in the stem of seed plants. Biol. Rev. 40: 534-579.

REeve, R. M. 1948. The "Tunica-corpus" concept and development of shoot apices in certain dicotyledons. Amer. J. Bot. 35: 65-75.

Rouffa, A. S., AND J. E. Gunckel. 1951a. A comparative study of vegetative shoot apices in the Rosaceae. Amer. J. Bot, 38: 290-300.

— AND - - 1951b. Leaf initiation, origin, and pattern of pith development in the Rosaceae. Amer. J. Bot. 38: 301-306.

S.sS, J. E. 1958. Botanical microtechnique. 3rd ed. Iowa State Univ. Press, Ames.

Scott, L. I., AND J. H. Priestly. 1925. Leaf and stem anatomy of Tradescantia fuminensis, Vell. J. Linn. Soc. London Bot. 47: 1-28. 